\title{
The Effect of Farm Supply Shifts on Concentration and Market Power in the Food Processing Sector
}

\author{
Stephen F. Hamilton and David L. Sunding
}

\begin{abstract}
In this paper we examine the marginal impact of changing farm supply on the market structure of the downstream food processing sector. We develop a theoretical model that allows for cost differences among processors and endogenizes downstream entry and exit. Comparative statics results are consistent with several well-established trends in the food processing sector. In particular, the analysis demonstrates that increasing concentration in the food processing sector is consistent with decreasing market power. Indeed, we find that when the farm supply curve shifts outward, an increase in concentration can only occur when there is a decrease in market power.
\end{abstract}

Key words: concentration, market power, oligopsony, supply shifts.

Technical innovation leading to lower farm production costs has been a hallmark of American agriculture, due in large part to the effectiveness of public research and extension activities (Chavas and Cox, Cochrane). Technological regress also occurs in the farm sector as a result of environmental regulations such as bans on agricultural chemicals that increase marginal production costs (Ebel, Hornbaker, and Nelson; Forsythe and Corso; Lichtenberg, Parker, and Zilberman; Sunding). Other well-known factors, such as insurance and stabilization programs, labor supply disruptions, land market fluctuations, and the supply of rural credit, also affect the position of the farm supply curve. In this paper we characterize the marginal impact of farm supply shifts on the market structure of a downstream food processing industry. Understanding the effect of farm supply shifts on the food processing sector is clearly important, particularly given the growing size of the processing industry and its significant impact on farmer and consumer welfare.

The problem of oligopsonistic competition in food processing has been analyzed recently by

\footnotetext{
Stephen F. Hamilton is assistant professor in the Department of Agricultural Economics at Kansas State University. David L. Sunding is associate professor in the Department of Agricultural and Resource Economics at the University of California, Berkeley.

This research was supported by a grant from the California Department of Food and Agriculture. The authors acknowledge helpful comments from Jeff Perloff, David Zilberman, and Richard Sexton
}

Chen and Lent, Just and Chern, Sexton, and Wann and Sexton. Unlike these previous studies of the food processing sector, the model presented in this paper allows for the possibility of cost differences among processors and endogenizes entry and exit. Clearly, these modifications are realistic. They also affect the results in important ways. A main finding of Chen and Lent, which is the paper most similar to ours, is that the farm price can increase when the farm supply curve shifts outward. This outcome occurs only when individual processing firms greatly expand output in response to the shift. Our model shows that an increase in the farm price in response to an outward shift of the farm supply curve is much more likely than Chen and Lent imply, since an outward shift in farm supply also stimulates entry in the food processing sector. Our model also reverses Chen and Lent's finding that processor profit decreases following an outward shift in farm supply only when the farm price increases. In our framework, an increase in the farm price unambiguously increases profits in the processing sector, since an increase in the farm price disproportionately affects inefficient processors and leads to higher profits for efficient processors.

Our model also helps reconcile some well-established but seemingly contradictory empirical results regarding the food processing industry. Economists have noted with some alarm the recent increases in concentration in the U.S. food 
processing sector. This concern arises from the belief that increased concentration implies increased anticompetitive behavior and an associated reduction in the price of farm products. Yet, counterintuitively, economists have also discovered decreasing levels of market power in food processing industries. Evidence from the meatpacking industry illustrates this paradox well. Koontz, Garcia, and Hudson find that meatpacker concentration increased in the fed cattle industry between the $1980-82$ period and the 1984-86 period, while, overall, market power decreased. Azzam and Schroeter simulate the impact of increased concentration in the beef packing industry on live cattle prices but find the price impact, and hence the market power, to be small due to a high estimated input supply elasticity. Finally, Schroeter and Azzam identify a trend toward decreasing market power in the hog processing industry during the period of increasing market concentration from 1976-1988. None of these studies attempts to reconcile the empirical regularity of increasing concentration and decreasing market power in food processing industries.

In the present paper we show that increasing concentration and decreasing market power in a processing industry are likely to occur simultaneously in response to a shift in farm supply. Indeed, we find that when the farm supply curve shifts outward, an increase in concentration only occurs when there is a decrease in market power. When the farm supply curve is inelastic, for example, market power in the processing sector is high, the farm price is low, and a large number of inefficient firms are able to produce. When the supply curve rotates clockwise, however, market power decreases and the farm price increases, which precipitates the exit of inefficient processors from the market, thereby increasing concentration.

The paper is structured as follows. In the next section, a theoretical model of oligopsony is developed with reference to the food processing industry. The model accounts for differences in productive efficiency between firms and explicitly allows for entry and exit. The third section presents comparative statics effects of a shift in farm supply on market share, market power, the price of farm products, processor profit, and the equilibrium number of firms. In the final section, conclusions are drawn.

\section{Model}

Consider an industry with $N$ oligopsonistically competitive food processors. Each firm pro- duces a homogeneous product $(y)$, using a raw farm product input $(x)$. Firm $i$ has the firm-specific production function

$$
\text { (1) } y^{i}=f^{i}\left(x^{i}\right)
$$

where $f^{i}\left(x^{i}\right)$ may differ from the production function of firm $j, \forall i \neq j$. Firm $i$ may have higher marginal productivity due to scale economies, to greater managerial efficiency, or to the ownership of specific rent-generating factors such as patents.

The difference in productive efficiency between processors is described by the following condition: Firm $i$ is more efficient in production than firm $j$ whenever

$$
\left.\frac{\partial f^{i}\left(x^{i}\right)}{\partial x^{i}}\right|_{x^{i *}}>\left.\frac{\partial f^{j}\left(x^{j}\right)}{\partial x^{j}}\right|_{x^{j *}}
$$

Condition $(\mathrm{C} 1)$ states that the marginal product of firm $i$ is greater than the marginal product of firm $j$ at the respective equilibrium levels of input use, $x^{i *}$ and $x^{j *}$. Also, since we wish to derive the comparative statics effects of a shift in farm supply, it is necessary to define the relative productive efficiency of processors with respect to marginal changes in output. Specifically, we wish to eliminate from consideration the somewhat unusual case in which a small, relatively inefficient processor has a lower marginal product than a large processor, yet has a greater capacity to expand production. We maintain the identity of firms by assuming that a change in raw product use does not cause the inefficient processor to expand output more cost-effectively than the efficient processor:

$$
\left.\frac{\partial^{2} f^{i}\left(x^{i}\right)}{\partial\left(x^{i}\right)^{2}}\right|_{x^{i *}} \geq\left.\frac{\partial^{2} f^{j}\left(x^{j}\right)}{\partial\left(x^{j}\right)^{2}}\right|_{x^{j *}}
$$

Condition (C2) is imposed in order to avoid ambiguity when we refer to the efficient firm and it is a sufficient condition, though not necessary, for the results that follow. ${ }^{1}$

Profit-maximizing behavior for all food processors is assumed. For firm $i$, the profit function is written as

\footnotetext{
1 The reader should note that condition (C2) is likely to be met in practical applications. Efficient processors may have lower marginal productivity at low levels of output, yet be operating at a scale that is well beyond any crossing of marginal productivity curves with relatively inefficient processors.
} 


$$
\pi^{\mathrm{i}}=P y^{i}-W(X) x^{i}-F^{i}
$$

where $P$ is the price of final food products, $W(X)$ is the inverse supply function for raw products, $X$ is the sum of all farm products purchased by processors, and $F^{i}$ is the firm-specific fixed cost of processor $i$, a portion of which may be sunk.

Processor $i$ chooses the level of raw products that maximize profit given by equation (2), subject to the production constraint in equation (1). Substituting the production function of processor $i$ into the profit function of the $i$ th firm allows us to calculate first- and second-order conditions for maximization,

$$
\pi_{x}^{i}=P f_{x}^{i}-W-W_{x} x^{i}=0
$$

and

$$
\pi_{x x}^{i}=P f_{x x}^{i}-2 W_{x}-W_{x x} x^{i}<0
$$

where identical conditions hold for firm $j$.

To address the possibility of entry in the model, the number of firms in the industry is treated as a continuous variable following Besley, Mankiw and Whinston, and Seade. Entry (exit) in a food processing industry occurs until processor profits are driven to zero. When processors are characterized by differences in productive efficiency, however, their profit expressions differ in equilibrium; low-cost processors receive efficiency rents, and the zero profit condition may bind only on the least efficient processor(s). A shift in the farm supply curve thus creates entry (exit) by altering the profit margin of the least efficient processors in the industry. While the entry of low-cost processors is likely to occur in the industry over time, the entry incentive of efficient firms exists regardless of a marginal shift in farm supply. We do not attempt to reconcile the fact that differences in productive efficiency are often observed in processing industries but, instead, begin the analysis from a baseline equilibrium in which both low- and high-cost producers exist a priori. The number of low-cost firms is exogenous, thereby allowing the effect of a marginal shift in farm supply on the entry (exit) incentive of high-cost processors to be isolated from the long-run entry incentive of efficient firms. Without imposing restrictions on the entry of low-cost firms, the model degenerates to a homogeneous firm equilibrium in which only efficient firms produce.
For simplicity, firms in the baseline equilibrium are partitioned into two groups: $m$ "efficient," or low-cost processors that each choose raw product use of $x^{l}$; and $n$ "inefficient," or high-cost processors that each choose raw product use of $x^{h}$. The aggregate use of raw products in the processing industry, then, is the sum of raw products purchased by all firms, $X=n x^{h}+$ $m x^{l}$.

It is now possible to focus attention on individual processor groups by inspecting the firstorder conditions of a representative low- and high-cost firm:

$$
\pi_{x l}^{l}=P f_{x}^{l}-W-W_{x} x^{l}=0
$$

and

$$
\pi_{x h}^{h}=P f_{x}^{h}-W-W_{x} x^{h}=0
$$

where the second-order conditions for each representative firm are analogous extensions of expression (4).

We assume that the industry is initially in equilibrium. In equilibrium, the number of high-cost processors in the industry, $n^{*}$, must satisfy

$$
\pi^{h}=P f^{h}\left(x^{h^{*}}\right)-W\left(X^{*}\right) x^{h^{*}}-F^{h}=0 .
$$

The equilibrium value of $n^{*}$ is determined simultaneously with $x^{l^{*}}$ and $x^{h^{*}}$ in equations (3a), (3b), and (5). It is assumed that $n^{*}$ is unique, as is the case when at least a portion of fixed costs are sunk (Besley, Vickers).

\section{Effect of a Farm Supply Shift}

Let $\theta$ be a shift parameter in the farm supply function; that is, $W=W(X ; \theta)$. This formulation of the supply shift parameter follows Chen and Lent, Dixit, and Quirmbach. The inverse supply function is written for the case of asymmetriccost oligopsony with reference to the output level of each representative firm by letting $\delta$ denote the output of low-cost competitors and by letting $\gamma$ denote the output of high-cost competitors;

$$
W=W\left(x^{h}+(n-1) \gamma+x^{l}+(m-1) \delta ; \theta\right)
$$

where the substitution has been made for total raw product use, $X$, and where $\delta$ and $\gamma$ are introduced purely for notational convenience. 
It is now possible to totally differentiate equations (3a), (3b), and (5), making use of expression (6) and the identities $\delta=x^{l}$ and $\gamma=x^{h}$. Combining equations, the system is written as

$$
\begin{aligned}
& {\left[\begin{array}{ccc}
\pi_{x_{l} x_{i}}^{l}+\pi_{x_{i} \delta}^{l} & \pi_{x_{1} x_{h}}^{l}+\pi_{x_{l} \gamma}^{l} & \pi_{x_{l} n}^{l} \\
\pi_{x_{h} x_{i}}^{h}+\pi_{x_{h} \delta}^{h} & \pi_{x_{h} x_{n}}^{h}+\pi_{x_{h} \gamma}^{h} & \pi_{x_{h} n}^{h} \\
\pi_{x_{i}}^{h}+\pi_{\delta}^{h} & \pi_{\gamma}^{h} & \pi_{n}^{h}
\end{array}\right]\left[\begin{array}{c}
d x^{l} \\
d x^{h} \\
d n
\end{array}\right]} \\
& =-\left[\begin{array}{l}
\pi_{x \theta \theta}^{l} \\
\pi_{x h \theta}^{h} \\
\pi_{\theta}^{h}
\end{array}\right] d \theta .
\end{aligned}
$$

Evaluating the determinant of the coefficient matrix (7) yields

$$
\begin{aligned}
D & =-\left(x^{h}\right)^{2} W_{x}\left(P f_{x x}^{l}-W_{x}\right)\left[P f_{x x}^{h}-2 W_{x}-x^{h} W_{x x}\right] \\
& =-\left(x^{h}\right)^{2} W_{x} V^{l} \pi_{x_{h} x_{h}}^{h}<0,
\end{aligned}
$$

where $V^{i}=P f_{x x}^{i}-W_{x}<0$ and where $\pi_{x_{h} x_{h}}^{h}<0$ is the second-order condition for the representative high-cost firm.

In the analysis that follows, it is useful to express the cross-elasticity of the marginal input supply function with respect to $W_{x}$ and $W_{\theta}$ as $\Phi$ $=\left[W_{\theta} W_{x x}-W_{x} W_{x \theta}\right] .^{2}$ The effect of a supply shift on the raw product use of the representative high-cost and low-cost firm is

$$
\frac{d x^{h}}{d \theta}=\frac{\left(x^{h}\right)^{3}\left\{V^{l} \Phi\right\}}{D}
$$

and

$$
\frac{d x^{l}}{d \theta}=\frac{\left(x^{h}\right)^{2}}{D}\left\{\left[x^{1} V^{h}-W_{x}\left(x^{1}-x^{h}\right)\right] \Phi\right\}
$$

where $W_{x} \geq 0$ and where the inequality $x^{1}-x^{h}>$ 0 follows from first-order conditions (3a) and ( $3 b)$ imposing condition (C1). Note that the sign of each expression depends on the sign of $\Phi$, as both types of firms unambiguously expand output whenever $\Phi>0$ and contract when $\boldsymbol{\Phi}<0$. Thus, during periods of outward farm supply shifts $\left(W_{\theta} \leq 0\right)$, when the farm supply

\footnotetext{
${ }^{2}$ That is, $\Phi=(\eta-1) W_{x} W_{x \theta}$, where $\eta=\left(W_{\theta} W_{x x}\right) /\left(W_{x} W_{x \theta}\right)$ is the cross-elasticity of $W_{x}$ and $W_{\theta}$.
}

curve is weakly concave $\left(W_{x x} \leq 0\right)$ and becomes more elastic following the shift $\left(W_{x \theta}<0\right)$, both low- and high-cost processors increase their use of raw products. An outward shift in the farm supply curve reduces the raw product use of incumbent firms when $\Phi<0$. $^{3}$

The effect of the supply shift on the equilibrium number of high-cost firms is

$$
\begin{aligned}
& \text { (10) } \frac{d n}{d \theta}=\frac{x^{h}}{D}\left\{W_{\theta} V^{1} \pi_{x h x h}^{h}\right. \\
& \left.-\Phi\left[(n-1) x^{h} V^{l}+m\left(x^{l} V^{h}-W_{x}\left(x^{l}-x^{h}\right)\right)\right]\right\}
\end{aligned}
$$

where the expression in square brackets is negative. Following an outward shift in farm supply, expression (10) is negative; that is, high-cost firms exit only under conditions that determine expansion in equations (8) and (9).

The effect of the supply shift on the industry use of raw products is expressed as

$$
\begin{aligned}
\frac{d X}{d \theta} & =x^{h}\left(\frac{d n}{d \theta}\right)+n\left(\frac{d x^{h}}{d \theta}\right)+m\left(\frac{d x^{1}}{d \theta}\right) \\
& =\frac{\left(x^{h}\right)^{2} V^{l}}{D}\left\{W_{\theta} \pi_{x h r h}^{h}+\Phi x^{h}\right\} .
\end{aligned}
$$

Expression (11) shows that the use of raw products unambiguously increases in a period of farm supply expansion whenever $\Phi \geq 0$. Conversely, an outward shift in the farm supply curve results in a smaller use of raw products in the sector when

$$
W_{x \theta} \geq \frac{W_{\theta}\left[V^{h}-W_{x}\right]}{x^{h}}
$$

This perverse effect occurs when the farm supply shift has a small outward level effect relative to an inelastic rotation effect.

The effect of a supply shift on the equilibrium farm price is

$$
\frac{d W^{*}}{d \theta}=W_{\theta}+W_{x}\left(\frac{d X^{*}}{d \theta}\right)=\frac{W_{x}\left(x^{h}\right)^{3} V^{\prime} \boldsymbol{\Phi}}{D}
$$

\footnotetext{
${ }^{3}$ Chen and Lent derive a similar condition for a symmetric-firm oligopsony.
} 
where the effect is positive or negative depending on the value of $\boldsymbol{\Phi}$. Positive values of $\boldsymbol{\Phi}$ in the model unambiguously lead to an increase in the farm price.

It is now possible to examine the effect of the supply shift on the market share of individual firms. Defining the market share of firm $i$ as $r^{i}$ $=\left(x^{i} / X\right)$, the change in market share is calculated for each type of firm as

$$
\frac{d r^{i}}{d \theta}=\frac{d\left(x^{i} / X\right)}{d \theta}=\frac{\left[X\left(d x^{i} / d \theta\right)-x^{i}(d X / d \theta)\right]}{X^{2}}
$$

so that the market share of a representative firm in each group is given by

$$
\frac{d r^{h}}{d \theta}=\frac{\left(r^{h}\right)^{2} x^{h} V^{l}}{D}\left\{-W_{\theta} \pi_{x h x h}^{h}+\Phi\left(X-x^{h}\right)\right\}
$$

and

$$
\begin{aligned}
& \text { (14) } \frac{d r^{l}}{d \theta}=\frac{-r^{h} x^{h}}{D}\left\{r^{l} V^{l} W_{\theta} \pi_{x x h h}^{h}\right. \\
& \left.+\Phi\left[x^{l}\left(P\left(f_{x x}^{l}-f_{x x}^{h}\right)-\left(1-r^{h}\right) V^{l}\right)+W_{x}\left(x^{l}-x^{h}\right)\right]\right\}
\end{aligned}
$$

In a period of farm supply expansion, the first term in each expression represents the loss of market share for each type of processor, as an outward shift of the supply curve stimulates entry of high-cost firms. In expression (14), note that the term in square brackets is positive by condition ( $\mathrm{C} 2)$, while the first term is negative. Hence, the market share of incumbent firms only increases following an outward shift of the farm supply curve when $\Phi>0$.

We next construct a measure for market power, recognizing that the market power of low-cost firms differs from that of high-cost firms due to differences in productive efficiency. Consequently, we restrict attention to low-cost processors and define market power by the ratio between the profit margin and price, or the Lerner index, for a representative low-cost firm,

$$
L^{l}=\frac{P f_{x}^{l}-W}{W} .
$$

This expression is analogous to the Lerner index of oligopoly power used by Appelbaum and, in this context, represents the degree of market power of the largest, most efficient firms. ${ }^{4}$ It is easily verifiable that

$$
L^{l}=\frac{r^{l}}{\varepsilon}
$$

where $\varepsilon=(d X / d W)(W / X)$ is the elasticity of farm supply. Expression (15) is equivalent to the measure used by Chen and Lent for the case of Cournot conjectures where we have replaced the Herfindahl index with the $m$-firm concentration measure $C R_{m}$. The effect of a farm supply shift on the market power of low-cost firms is

$$
\begin{aligned}
\frac{d L^{l}}{d \theta}= & \left\{\frac{W_{x}}{W}\left(\frac{d x^{l}}{d \theta}\right)+\frac{x^{l}}{W}\left[W_{x \theta}+W_{x x}\left(\frac{d X}{d \theta}\right)\right]\right. \\
& \left.-\frac{x^{l} W_{x}}{W^{2}}\left[W_{\theta}+W_{x}\left(\frac{d X}{d \theta}\right)\right]\right\}
\end{aligned}
$$

which yields

$$
\begin{aligned}
\frac{d L^{l}}{d \theta} & =\frac{\left(x^{h}\right)^{2} \Phi}{D W^{2}}\left\{P f_{x x}^{l} x^{l}\left[W V^{h}-W_{x}\left(W+x^{h} W_{x}\right)\right]\right. \\
& \left.+W_{x}^{2} x^{h}\left(W+x^{l} W_{x}\right)\right\}
\end{aligned}
$$

where the entire bracketed term is unambiguously positive. Thus, the change in market power for the representative low-cost firm is inversely related to $\Phi$.

It is also useful to analyze the effect of a supply shift on the profit of a representative low-cost processor. ${ }^{5}$ The effect of a supply shift on the profit of a representative low-cost processor is

$$
\begin{aligned}
& \frac{d \pi^{l}}{d \theta}=\left[P f_{x}^{l}-W\right]\left(\frac{d x^{l}}{d \theta}\right)-x^{l}\left(\frac{d W^{*}}{d \theta}\right) \\
= & \frac{\left(x^{h}\right)^{2} \Phi}{D}\left\{W_{x} x^{l}\left[x^{l} V^{h}-x^{h} V^{l}-W_{x}\left(x^{l}-x^{h}\right)\right]\right\}
\end{aligned}
$$

where the substitution $P f_{x}^{l}-W=W_{x} x^{l}$ is made using first-order condition (3a) and where the

\footnotetext{
${ }^{4}$ Another alternative would be to use a weighted average of the Lerner index to capture the degree of market power of a single representative firm. This approach, however, would be somewhat misleading as it would understate the market power of low-cost producers and overstate that of high-cost producers.

${ }^{5}$ Note that the profit effect for low-cost processors also captures the entire profit effect in the processing sector, since only low-cost processors have positive profit in equilibrium.
} 
Table 1. Contingent Outcomes of a Shift in Farm Input Supply

\begin{tabular}{|c|c|c|c|c|c|}
\hline & $d n / d \theta$ & $d r^{l} / d \theta$ & $d W^{*} / d \theta$ & $d L^{l} / d \theta$ & $d \pi^{1} / d \theta$ \\
\hline \multicolumn{6}{|l|}{ No shift } \\
\hline$W_{x \theta}=0$ & 0 & 0 & 0 & 0 & 0 \\
\hline$W_{x \theta}<0$ & - & + & + & - & + \\
\hline$W_{x \theta}>0$ & + & - & - & + & - \\
\hline \multicolumn{6}{|l|}{ Outward shift } \\
\hline$\Phi=0$ & + & - & 0 & 0 & 0 \\
\hline$\Phi>0$ &,,+- or 0 &,,+- or 0 & + & - & + \\
\hline$\Phi<0$ & + & - & - & + & - \\
\hline \multicolumn{6}{|l|}{ Inward shift } \\
\hline$\Phi=0$ & - & + & 0 & 0 & 0 \\
\hline$\Phi>0$ & - & + & + & - & + \\
\hline$\Phi<0$ &,,+- or 0 &,,+- or 0 & - & + & - \\
\hline
\end{tabular}

expression in brackets is negative by conditions (C1) and (C2). Hence, profits increase only when $\Phi>0$, a case associated with decreased market power and an increase in the farm price. The implication of expression (17) is exactly the opposite of that of Chen and Lent, who find a negative profit effect in cases where the farm price increases. Our model generates the opposite result due to cost asymmetry between firms and to entry conditions in the industry. That is, while an increase in the farm price directly decreases the profitability of low-cost firms through equation ( $3 a$ ), a higher farm price affects high-cost firms to a greater degree in equation ( $3 b$ ) and leads, in most instances, to the exit of high-cost processors from the market through expression (5). Counterintuitively, the net effect of an increase in the farm price is to improve the profitability of low-cost processors.

Using expressions (12) through (17), it is possible to draw inferences relating the shift in farm supply to changes in the structural competitiveness of the food processing sector. Contingent outcomes of the model are presented in table 1 . In the table, we consider the cases that arise under alternate values of $W_{\theta}$ and $\Phi$. When $W_{\theta}=0$, the case is one of a rotation, but not a shift in farm supply, while values of $W_{\theta}<0$ and $W_{\theta}>0$ represent an outward shift and inward shift of the farm supply curve respectively. All three types of supply shift can occur as a result of technological progress or regress in the farm sector.

The influence of alternate values of $\Phi$ on market structure can be seen most clearly when the shift in farm supply is suppressed. When $W_{\theta}$ $=0$, the market structure in the food processing industry depends critically on the change in elasticity of the farm supply curve. When the farm supply curve becomes more elastic as a result of technical change $\left(W_{x \theta}<0\right)$, the equilibrium price of raw products rises, profits increase in the processing sector, high-cost processors exit the industry, incumbent firms expand production, and concentration increases. Market power, however, declines. When the shift in farm supply is suppressed, the first term drops out of market share expressions (13) and (14) and concentration and market power is inversely related in the industry. In cases where the supply curve is inelastic, a high degree of market power exists in the industry, yet an incumbent that expands output slightly at the margin suffers a large increase in the price of raw products relative to the case of elastic supply. Thus, the equilibrium farm price tend to be low (and marginal product high) relative to the case of elastic supply, which allows a larger number of high-cost firms to produce. Conversely, when technical change causes the supply of raw products to become more elastic, the farm supply curve is able to more readily absorb increases in production without creating large, commensurate increases in the price of raw products. Incumbent firms consequently expand their use of raw products, increasing the farm price and precipitating the exit of highcost firms in the industry. Suppressing level effects in the supply of raw products, a clockwise rotation of the farm supply curve leads to decreased market power but also to output expansion by low-cost firms, to exit by high-cost firms, and, hence, to increased market concentration.

When technological progress occurs in the farm sector, a positive value of $\Phi$ occurs in cases when the farm supply curve becomes 
more elastic following the outward shift in supply, or, alternately, when the farm supply curve is concave $\left(W_{x x}<0\right)$. When the farm supply curve is concave, an efficient firm is positioned on a more elastic portion of the marginal input cost curve than an inefficient firm and thus adjusts its raw product use to a greater degree in order to restore its first-order condition. ${ }^{6}$ Therefore, a concave farm supply curve gives efficient producers greater incentive to expand output in periods of technological progress while in periods of technological regress the converse situation arises and efficient firms contract output relative to inefficient firms.

Now consider the impact of technical innovation in the farm sector. In this case, a level effect shifts the farm supply curve outward by the first term in expressions (10) through (14), stimulating the entry of inefficient firms, raising the aggregate use of raw products, and decreasing the market share of incumbent firms. These effects are strengthened when the farm supply curve is convex and becomes more inelastic following the shift but countervailed when the supply curve is concave and rotates in a clockwise direction. Consequently, the observed increase in food processing market concentration is consistent with an outward shift in farm supply only when $\Phi>0$, which occurs when the farm supply function is concave or when farm supply becomes more elastic following the shift. Yet, whenever $\Phi>0$, the market power of low-cost processors unambiguously declines. An outward shift and clockwise rotation of the farm supply curve is thus consistent with the observed inverse relationship between concentration and market power in the food processing sector.

When $\Phi>0$, the farm price increases and a positive profit effect occurs in the processing industry. For example, when the farm supply curve rotates in a clockwise direction but does not shift, the effect is to stimulate an output expansion by low-cost firms which pushes up the equilibrium price of farm products yet increases industry profit as high-cost firms exit the market. Counterintuitively, a positive price effect not only increases welfare in the farm sector but also leads to increased profitability in the processing sector itself. Such an outcome is only possible in a model that endogenizes entry and exit.

The model also can be used to assess welfare

\footnotetext{
- Similar intuition is provided for the case of oligopoly by Dierickx, Matutes, and Neven and by Hamilton and Sandin.
}

implications of alternative farm policies. Consider, for example, the effect of a farm output subsidy. A per unit subsidy on raw products shifts the farm supply curve outward in a parallel fashion $\left(W_{\theta}<0\right.$ and $\left.W_{x \theta}=0\right)$. When the farm supply curve is convex, a unit subsidy stimulates the entry of high-cost firms, decreases concentration, increases market power, decreases the equilibrium price of raw products, and reduces profit in the processing sector. When the farm supply curve is linear $(\Phi=0)$, a unit subsidy on raw products causes high-cost processors to enter the industry and leads to decreased concentration, while market power, low-cost processor profit, and the farm price remain constant. When the farm supply curve is concave, a unit subsidy decreases market power, increases the equilibrium farm price, and reduces low-cost processor profits, yet a subsidy has an ambiguous effect on processor entry and on industry concentration. A unit tax has the opposite effect in each case.

\section{Discussion}

The main purpose of this paper is to examine the effect of a farm supply shift on the market structure of an oligopsonistically competitive processing industry. We demonstrate that a broad range of outcomes is possible, depending on the convexity of the farm supply function, the direction of the level effect, and the change in the elasticity of the farm supply curve created by the shift.

Theoretical explanation is provided to support the empirical regularity of simultaneously increasing concentration and decreasing market power in the food processing sector. Indeed, diminished market power is demonstrated to be a necessary condition for increasing concentration in a regime of expanding raw product supply. When there is technological progress in the farm sector, a positive level effect in farm supply creates a tendency toward declining concentration in the processing industry as highcost processors enter. An outward shift only increases concentration in cases where the farm supply curve is concave or becomes more elastic as a result of the shift, conditions that are associated with decreased market power. A central hypothesis is that increased processor concentration occurs during a period of technological progress only if market power decreases.

The inverse relationship between market power and industry concentration occurs largely due to entry conditions in the model. 
When the entry of high-cost processors is unrestricted, industry concentration is shown to increase following an outward shift in farm supply only in cases where market power decreases. In other instances, such as when substantial entry barriers exist in food processing, behavior in the market may be less purely conditioned by entry incentives and it is possible that market power and industry concentration are positively related. While most welfare implications, such as price and profit effects, are related to the degree of market power in the industry, meaningful implications cannot arise from observing concentration measures alone. Future research is needed in individual processing industries to account for industry-specific factors such as entry that condition behavior in the market.

The model also has interesting implications for the welfare effects of farm policies. For example, price supports, research and development programs, agricultural chemical bans, and worker protection policies all affect the position of the farm supply curve. In order to adequately understand the ultimate impacts of these policies on farmer, processor, and consumer welfare, accurate modeling of the imperfectly competitive food processing sector is essential.

\section{References}

Appelbaum, E. "The Estimation of the Degree of Oligopoly Power." J Econometrics 19(August 1982):287-99.

Azzam, A., and J. Schroeter. "Implications of Increased Regional Concentration and Oligopsonistic Coordination in the Beef Packing Industry." W. J. Agr. Econ. 16(December 1991):374-81.

Besley, T. "Commodity Taxation and Imperfect Competition: A Note on the Effects of Entry." $J$. Public Econ. 40(December 1989):359-67.

Chavas, J.P., and T. Cox. "A Nonparametric Analysis of the Influence of Research on Agricultural Productivity." Amer. J. Agr. Econ. 74(August 1992):583-91.

Chen, Z., and R. Lent. "Supply Analysis in an Oligopsony Model." Amer. J. Agr. Econ. 74(November 1992):973-79.

Cochrane, W. The Development of American Agriculture. Minneapolis MN: University of Minnesota Press, 1979.

Dierickx, I., C. Matutes, and D. Neven. "Indirect
Taxation and Cournot Equilibrium." Int. J. Indust. Org. 6(September 1988): 385-99.

Dixit, A. "Comparative Statics for Oligopoly." Int. Econ. Rev. 27(February 1986):107-22.

Ebel, E., R. Hornbaker, and C. Nelson. "Welfare Effects of the National Pseudorabies Eradication Program." Amer. J. Agr. Econ. 74(August 1992):638-45.

Forsythe, K., and B. Corso. "Welfare Effects of the National Pseudorabies Eradication Program: Comment." Amer. J. Agr. Econ. 76(November 1994):968-71.

Hamilton, S., and R. Sandin. "Subsidies in Oligopoly Markets: A Welfare Comparison Between Symmetric and Asymmetric Costs." Public Finan. Rev., in press, 1997.

Just, R., and W. Chern. "Tomatoes, Technology, and Oligopsony." Bell J. Econ. 11(Autumn 1980):584-602.

Koontz, S., P. Garcia, and M. Hudson. "Meatpacker Conduct in Fed Cattle Pricing: An Investigation of Oligopsony Power." Amer. J. Agr. Econ. 75(August 1993):537-48.

Lichtenberg, E., D. Parker, and D. Zilberman. "Marginal Welfare Analysis of Welfare Costs of Environmental Policies: The Case of Pesticide Regulation." Amer. J. Agr. Econ. 70(November 1988):867-74.

Mankiw, N., and M. Whinston. "Free Entry and Social Inefficiency." Rand. J. Econ. 17(Spring 1986):48-58.

Quirmbach, H. "Comparative Statics for Oligopoly: Demand Shift Effects." Int. Econ. Rev. 29(August 1988):451-59.

Schroeter, J. "Estimating the Degree of Market Power in the Beef Packing Industry." Rev. Econ. Statist. 70(February 1988):158-62.

Schroeter, J., and A. Azzam. "Marketing Margins, Market Power, and Price Uncertainty." Amer. J. Agr. Econ. 73(November 1991):990-99.

Seade, J. "On the Effects of Entry." Econometrica 48(March 1980):479-89.

Sexton, R. "Imperfect Competition in Agricultural Markets and the Role of Cooperatives: A Spatial Analysis." Amer. J. Agr. Econ. 72(August 1990):709-20.

Sunding, D. "Measuring the Marginal Cost of Nonuniform Environmental Regulations." Amer. J. Agr. Econ. 78(November 1996):1098-1107.

Vickers, J. "The Nature of Costs and the Number of Firms at Cournot Equilibrium." Int. J. Indust. Org. 7(December 1989):503-09.

Wann, J., and R. Sexton. "Imperfect Competition in Multiproduct Food Industries with Application to Pear Processing." Amer. J. Agr. Econ. 74(November 1992):980-90. 